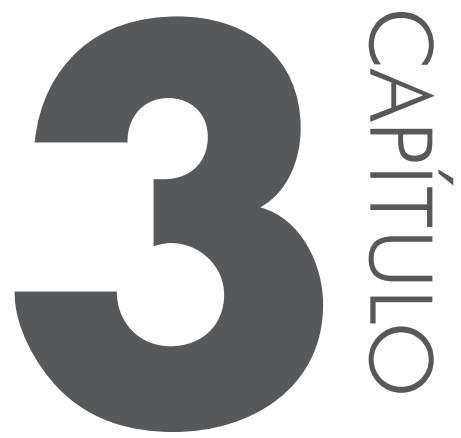

\title{
GEOTECNOLOGIAS: UMA ANÁLISE AMBIENTAL DA BACIA HIDROGRÁFICA DO RIBEIRÃO PONTE ALTA-MG, POR MEIO DE MAPEAMENTO TEMÁTICO
}

Loren Lucas Ribeiro João Donizete Lima

Resumo: A área a ser estudada no presente artigo é uma parte delimitada da bacia hidrográfica do Ribeirão Ponte Alta, considerado um bairro rural do $\mathrm{Mu}$ nicípio de Uberaba-MG. Foi utilizada uma imagem SRTM para calcular as cinco classes de declividade, em seguida da confecção dos mapas temáticos de declividade e hipsométrico. Para a confecção do mapa temático do uso e da ocupação da terra, utilizou-se uma imagem satélite TM Landsat 8 e 5 . O cálculo de decli- 
vidade agrupa-se dentro das classes de relevo conforme o manual de obtenção de terras do INCRA (2006). Esses cálculos tem o objetivo de realizar os primeiros diagnósticos de análise sobre o meio físico da área a ser estudada. A finalidade do mapa temático hipsométrico é relevante para ilustrar as características geomorfológicas da área a ser estudada. Os resultados mostraram que a área tem um relevo aplainado, apto para cultivo e plantações, o que explica os motivos de a região ser escolhida demasiadamente para obter plantações de cana-de-açúcar. Já onde o relevo se apresenta dissecado, há maior propensão à ocorrência de processos erosivos.

Palavras-chave: Geotecnologias. Declividade. Análise ambiental. Mapeamento.

Abstract: The area to be studied in this article, is a specific part of the watershed of Ribeirão Ponte Alta, considered a rural district of the city of Uberaba-MG. One SRTM image was used to calculate the five slope classes, then the preparation of thematic maps of slope and hypsometric. To make the thematic use and occupation of the land map, used a Landsat TM satellite image 8 e 5 . The slope calculation is grouped within the relevant classes according to the manual of obtaining land from INCRA (2006). These calculations aims to make the first analysis of diagnostics on the physical environment of the area being studied. The purpose of the hypsometric thematic map is relevant to illustrate the geomorphological characteristics of the area being studied. The results showed that the area has a flattened relief, fit for cultivation and plantations, that explains the reasons for the region be chosen for plantations of sugarcane too. Already where the relief is dissected, which are more prone to the occurrence of erosion.

Keywords: Geotecnology. Slope. Environmental analysis. Mapping.

\section{INTRODUC̣ÃO}

Nas últimas décadas, o homem vem se preocupando e repensando a maneira de conduzir a sua vida e, em especial, o meio ambiente. Infelizmente, as práticas antrópicas, de forma não sustentável, acabam colocando em risco a continuidade de sua própria existência.

Desta forma, uma maneira a ser pensada para tentar reverter e explicar certas ocorrências negativas, em nosso meio, é a amostragem da configuração do meio físico por meio da utilização dos mapeamentos temáticos, que é o objetivo do presente artigo.

Vale ressaltar que os mapas de declividade de escala 1:50.000, importantes neste estudo de avaliação ambiental, seguem os critérios e padrões da Carta Clinográfica, de De Biasi (1970) e baseiam-se nos intervalos em porcentagem propostos pelo INCRA (2006). 
A localização da área de estudo se concentra inclusa na bacia hidrográfica do Ribeirão Ponte Alta, no estado de Minas Gerais, entre as coordenadas LAT $19^{\circ}$

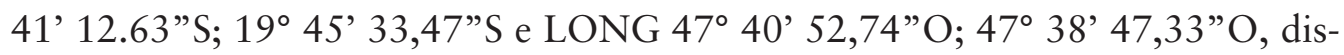
tando $30 \mathrm{~km}$ do centro da cidade de Uberaba-MG, saída a NE, dentro do limite de Ponte Alta seguindo pela estrada BR-262. Tem-se como recorte os córregos: Córrego Varizes dos Mangues, Córrego da Paz, Córrego Buracão, Córrego Gordura e a malha urbana de Ponte Alta-MG. A área total da bacia de estudo é de aproximadamente de $5,2 \mathrm{~km}^{2}$.

A metodologia do presente artigo, em resumo, usa uma imagem SRTM para calcular cinco classes de declividade, seguindo a base teórica De Biasi (1970) e os valores de análise de declividade propostos pelo INCRA (2006). Já para o mapa temático do uso e da ocupação da terra, utilizou-se a imagem satélite TM Landsat 8 e 5, e também foi utilizado o Google Earth, um software livre, para auxiliar no processo de identificação dos usos da área.

Foi elaborada uma tabela a partir das classes de relevo para calcular os valores de capacidade do uso do solo e posteriormente foi feita uma análise dos resultados. O mapa temático hipsométrico e o mapa temático de uso da terra são relevantes para ilustrar as características geomorfológicas da área de estudo.

Considerando essa premissa, este artigo visa, a partir do uso integrado de produtos e técnicas do sensoriamento remoto e geoprocessamento, avaliar espacialmente aspectos do uso e da ocupação da terra na área da bacia hidrográfica do Ribeirão Ponte Alta, de modo a estabelecer diretrizes para seu uso e sua ocupação.

\section{LOCALIZAC̣ÃO DA ÁREA}

Para o presente estudo, foi escolhido um trecho da bacia hidrográfica do Ribeirão Ponte Alta. Ponte Alta é considerado um bairro rural do Município de Uberaba-MG. Conforme a Lei Complementar n 413/2009, regulamentada pelo decreto 780/2009, Uberaba-MG possui 36 Unidades de Planejamento e Gestão Urbana (conhecidas como bairros) e nove Núcleos de Desenvolvimento Rural (conhecidos como bairros rurais), sendo Ponte Alta um destes nove núcleos de desenvolvimento (PREFEITURA MUNICIPAL DE UBERABA, 2008). O trevo de acesso ao bairro se faz por meio da rodovia BR-262, numa altitude de 993 metros (Figura 1).

A rodovia BR-262, que dá acesso ao bairro, serve como divisor de águas de duas importantes bacias: Bacia do Rio Uberaba e Bacia do Ribeirão Ponte Alta. Esses dois cursos d'água são afluentes do Rio Grande, rio este que divide o Triângulo Mineiro, região do estado de Minas Gerais, e o estado de São Paulo.

A região do alto curso da bacia hidrográfica do Ribeirão Ponte Alta tem relevância significativa para o Município de Uberaba-MG, uma vez que boa parte 
da região é marcada por ter seus solos vinculados a latossolos roxos estruturados provenientes da decomposição de basaltos da Formação Serra Geral. Essa mesma unidade encontra-se ainda confinada às maiores drenagens que dissecaram de forma mais intensa o relevo, formando, por vezes, vales profundos com cursos d'água encachoeirados.

Apresenta os solos de maior fertilidade dentre os três domínios, ocupados, essencialmente, por cana-de-açúcar, mas também se fazem presentes projetos agropecuários bovinos, equinos, asininos, sementes de soja e milho, associados à alta genética, em especial nas margens das rodovias, da divisa do estado de São Paulo até Uberaba.

Em escala geral, a caracterização geomorfológica de Ponte Alta-MG pode ser definida pela presença de chapadões, escarpas e topos arredondados, em um contexto em que há planaltos de altitudes, melhor classificados como Sub-Bacia Bauru. Ribeiro et al. (2010) ressaltam que tal caracterização atribui-se às litologias do Grupo Bauru, como as formações Marília e Uberaba, sobrepostas às rochas basálticas da Formação Serra Geral. Explorando a Formação Marília, pode-se encontrar um material inconsolidado que forma os chapadões, terrenos de maiores altitudes e menor declividade do Município.

\section{REVISÃO TEÓRICA}

As formas de uso e de ocupação do espaço urbano ou rural no Brasil têm provocado sucessivos e inúmeros problemas ambientais, que promovem intensas degradações ao meio ambiente, como: contaminação do solo e da água, poluição do ar, perda da capacidade de produtividade dos solos, erosão, entre tantos outros. E como consequências disto há um aumento de problemas como enchentes, deslizamentos, assoreamentos de rios, desertificações etc. (SANTOS, 2007).

A Geotecnologia em aplicações de mapeamento da declividade pode adotar tarefas metodológicas e simplificadas de geração de mapas temáticos, com o auxílio das técnicas do Sensoriamento Remoto e Geoprocessamento: Fitz (2008); Gianezini et al. (2012); Santos (2004); Silva e Zaidan (2012); Rosa e Brito (1996); Cardoso et al. (2010); Florenzano (2011).

No presente artigo, pode-se pontuar a agilidade e a rapidez da elaboração do mapa de declividade e do mapa hipsométrico para subsidiar o estudo de análise ambiental, seguindo a teoria de classificação das classes de declividade do terreno, em porcentagem, conforme De Biasi (1970).

$\mathrm{Na}$ metodologia, estão descritos alguns dos métodos que foram utilizados na pesquisa, com o intuito de auxiliarem na análise das diferentes variações topográficas. 


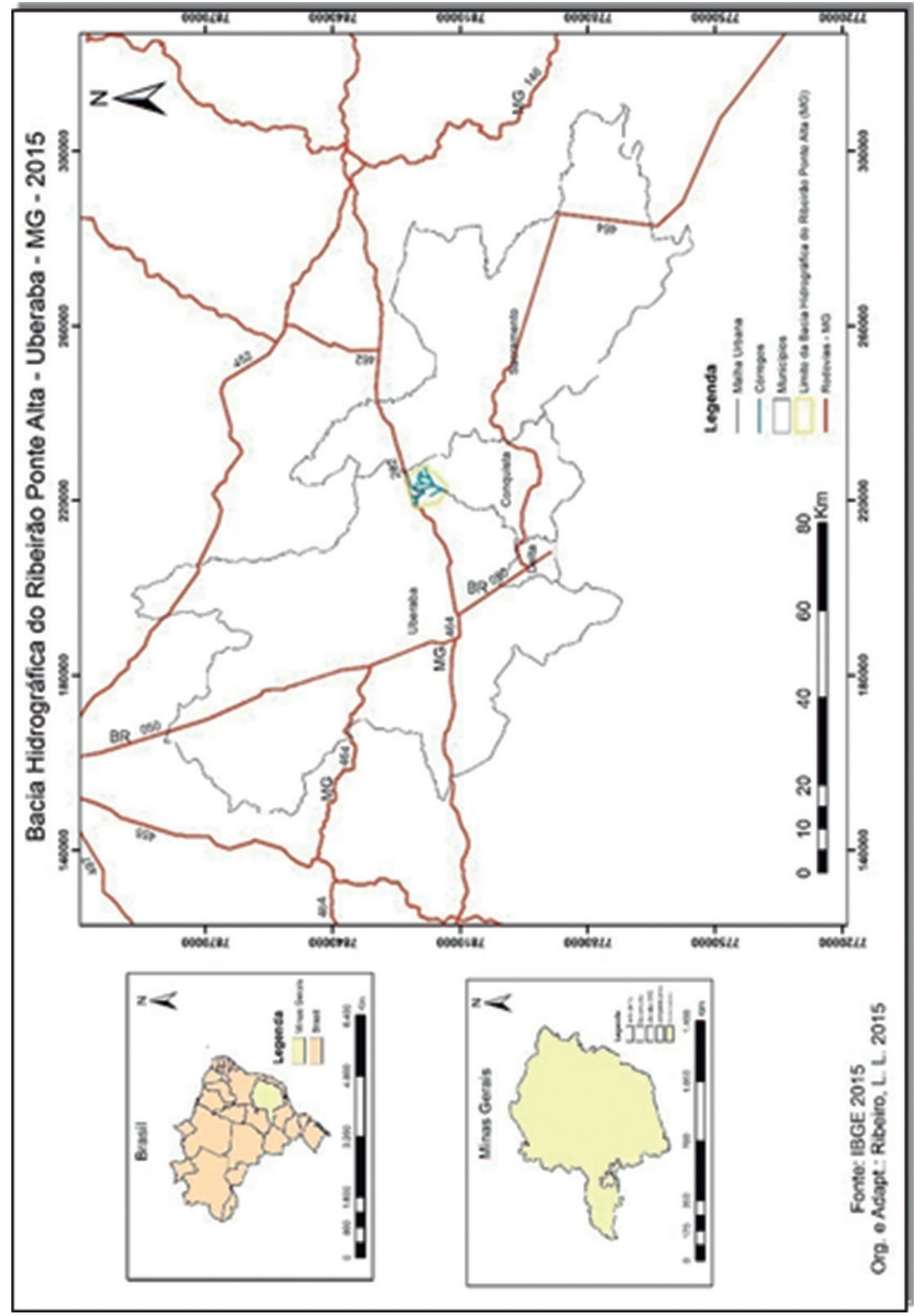

Figura 1. Localização da bacia hidrográfica do Ribeirão Ponte Alta. Fonte: adaptado de Ribeiro (2015). 
Por meio das análises do resultado realizado dos dados da confecção do mapa temático de uso e de ocupação da terra, pretende-se contribuir para fins de planejamento e para o melhor conhecimento da dinâmica da bacia hidrográfica do Ribeirão Ponte Alta-MG.

A Tabela 1 mostra os valores de referência para representação cartográfica, de acordo com a teoria de De Biasi (1970), e também com o INCRA (2006), que são: $0-2 \%$ (plano), $2-5 \%$ (suave ondulado), 5-10\% (moderadamente ondulado), $10-25 \%$ (ondulado), 15 - 45\% (forte ondulado), maior que $45 \%$ (montanhoso), e maior que 70\% (escarpado). Esses intervalos são estabelecidos conforme o grau de limitação de uso do solo em função da susceptibilidade à erosão.

A Tabela 2 exibe seis classes de capacidade de uso da terra conforme o manual de obtenção de terras e perícia judicial do INCRA.

Tabela 1. Classes de Capacidade de uso do solo conforme o Manual de obtenção de terras e perícias judicial do INCRA

\begin{tabular}{cc}
\hline Classes de Declividade & Classes do Relevo \\
\hline $0-2 \%$ & Plano \\
$2-5 \%$ & Suave Ondulado \\
$5-10 \%$ & Moderadamente Ondulado \\
$10-15 \%$ & Ondulado \\
$15-45 \%$ & Forte Ondulado \\
$45-70 \%$ & Montanhoso \\
$<70 \%$ & Escarpado \\
\hline
\end{tabular}

Fonte: INCRA (2006).

Tabela 2. Classes de Capacidade de uso da terra conforme o manual de obtenção de terras e perícia judicial do INCRA

\begin{tabular}{ccccccc}
\hline \multirow{2}{*}{ Capacidade de Uso } & $\mathrm{I}$ & $\mathrm{II}$ & $\mathrm{III}$ & $\mathrm{IV}$ & $\mathrm{V}$ & $\mathrm{VI}$ \\
& $100 \%$ & $80 \%$ & $61 \%$ & $47 \%$ & $39 \%$ & $29 \%$ \\
\hline
\end{tabular}

Fonte: INCRA (2006).

\section{METODOLOGIA}

A declividade é definida como a maior ou menor inclinação do relevo em relação ao horizonte, quanto maior a declividade de um relevo, maior o seu potencial de escoamento superficial; assim, as águas que correm nesse meio descem em alta velocidade e aumentam o poder erosivo. Assim, quanto menor a declividade, menor é o potencial de escoamento superficial e, consequentemente, menor o potencial erosivo. Porém, tem-se a tendência a acúmulo das águas e à deposição do material transportado pelos rios, o que facilita a ocorrência de inundações. 
O mapeamento do uso e da ocupação da terra é feito no sentido de disciplinar as atividades potencialmente nocivas ao meio ambiente e de promover formas adequadas de utilização dos espaços em concordância com suas capacidades de uso. Para isso, são utilizadas ferramentas capazes de auxiliar na gestão ambiental, com análises tanto qualitativas como quantitativas.

A metodologia deste artigo, em suma, consistiu em: 1) aquisição da imagem satélite SRTM dos produtos TOPODATA, e também de uma imagem satélite TM Landsat 8, utilizando o software Google Earth como apoio para a categorização da área no banco de dados. Posteriormente, houve importação da imagem para o Programa Arcgis 10.1®, pertencente ao LABEGEO - Laboratório de Geoprocessamento, da Universidade Federal de Goiás (Regional Catalão), georreferenciamento em UTM/WGS84; 2) elaboração dos mapas temáticos de declividade, hipsométrico e de uso e de ocupação da terra; 3) interpretação das tabelas; 4) conclusões sobre a situação na área de estudo do percentual das terras em termos de sua capacidade de uso.

O mapa de declividade foi gerado com escala de 1:50.000, utilizando-se a imagem SRTM, com resolução espacial de 30m, no programa Arcgis 10.1®, a partir do uso das técnicas slop e máscara $3 \times 3$, com o cálculo das classes $<5 \%$; $5-10 \% ; 10-20 \% ; 20-40 \%$ e $>40 \%$ (Figura 3 ). Por sua vez, o mapa temático de uso e de ocupação da terra foi gerado no referencial geodésico UTM Sirgas 2000.

Tratando-se do mapa temático de uso e ocupação da terra, após a realização da classificação supervisionada, alguns resultados podem ser questionados, devido ao fato de algumas classes terem um comportamento espectral próximo, como é o caso da vegetação natural com mata, pastagem e agricultura. Para a construção deste mapa, foi utilizado o software ArcGis 10®.

Para correção desses questionamentos, optou-se pelo recorte da imagem Landsat, com a dimensão apenas da área em estudo. Com isso, a classificação supervisionada foi mais específica em relação às classes. Ao transportar para o ArcGis 2010®, a determinação das classes foi mais bem definida, facilitando o processo de interpretação de ambas as imagens.

Foram realizadas visitas à área estudada, com o intuito de demarcar pontos com o uso de GPS de navegação, reconhecer as áreas utilizadas na antiga mineração, nas plantações de cana-de-açúcar, na pastagem e o crescimento da área urbana nas nascentes. As principais feições mapeadas foram registradas com uma câmera digital Câmera Fotográfica - SONY - Cyber-shot, com 26 mm 4 x de zoom óptico e 12.1 mega pixel.

Por fim, procedeu-se a digitalização da área utilizando-se a imagem Landsat-TM 8 e 5, com resolução espacial de 30 metros, de modo visual, digitalizando os polígonos em tela, baseando-se no levantamento de campo realizado. 
Foi confeccionado também um mapa temático de uso e de ocupação da terra do ano de 1985, com a imagem Landsat-TM 5, para avaliar o comportamento físico da área estudada durante o processo de urbanização e exploração de calcários.

Utilizou-se a imagem satélite TM Landsat-TM 8 para confeccionar o mapa de uso e de ocupação da terra do ano de 2015.

O motivo para se confeccionar dois mapeamentos temáticos de anos diferentes era poder comparar e avaliar o comportamento físico da área depois de 30 anos. Sabe-se que na região ocorreram várias atividades relacionadas à agropastagem e também à exploração de calcário.

\section{RESULTADOS E DISCUSSÕES}

Como resultado do presente artigo foram então gerados quatro mapas temáticos: Mapa Hipsométrico; Mapa de declividade; e dois mapas de uso e de ocupação da terra, um de 2015 e outro de 1985.

O mapa de declividade consiste em cinco classes: $<5 \% ; 5-10 \% ; 10-20 \%$; $20-40 \%$ e $>40 \%$. Essas classes que obedecem aos intervalos estabelecidos pelo INCRA (2006), o qual define as classes de relevo em função da declividade, correspondem à capacidade de uso de cada classe de relevo (ver Figura 2).

Ao analisar a imagem, nota-se que o núcleo urbano do bairro de Ponte Alta-MG foi inserido nas cabeceiras e margens dos córregos existentes na área. Na porção noroeste do mapa, próxima às cabeceiras das nascentes dos córregos, existia uma exploração de calcário, que, associada ao tipo de solo da região - latossolo vermelho amarelo, profundo e bastante friável -, acarretou sérios problemas erosivos na área.

De acordo com as Tabelas 1 e 2, nota-se que no centro da área estão áreas mais aplainadas, cuja classificação pode ser descrita como relevo plano, pertencente à classe $<5 \%$, que corresponde à classe I, com capacidade de uso da terra de $100 \%$.

As nascentes estão posicionadas nas classes de $>40 \%$, o que representa um relevo forte ondulado, suscetível ao surgimento de processos erosivos, originados pelo escoamento superficial difuso. Estas características correspondem à classe III, ou seja, representa $61 \%$, o que significa que estes solos, sem os devidos cuidados ao serem cultivados, podem sofrer degradação rápida e requerer medidas complexas.

Pode-se analisar que o meio físico da área estudada tem como características um relevo mais dissecado. Conforme análise da Figura 3, vemos um núcleo urbanizado do bairro Ponte Alta; do lado direito da BR-262 (sentido Uberaba-Araxá), as serras existentes na região de estudo possuem áreas de extensas nascentes, em forma de anfiteatros e contornam toda a porção norte do bairro. Neste lado, nasce o ribeirão Ponte Alta, um canal fluvial, de vazão rápida, que corre pelos vales estreitos do relevo. Com isso, seu poder erosivo é maior, o que nos revela a preocupação com a preservação das matas, com o planejamento das plantações, das construções das estradas e da extração de minérios, uma vez que a região sofreu com a extração de calcário há alguns anos. 


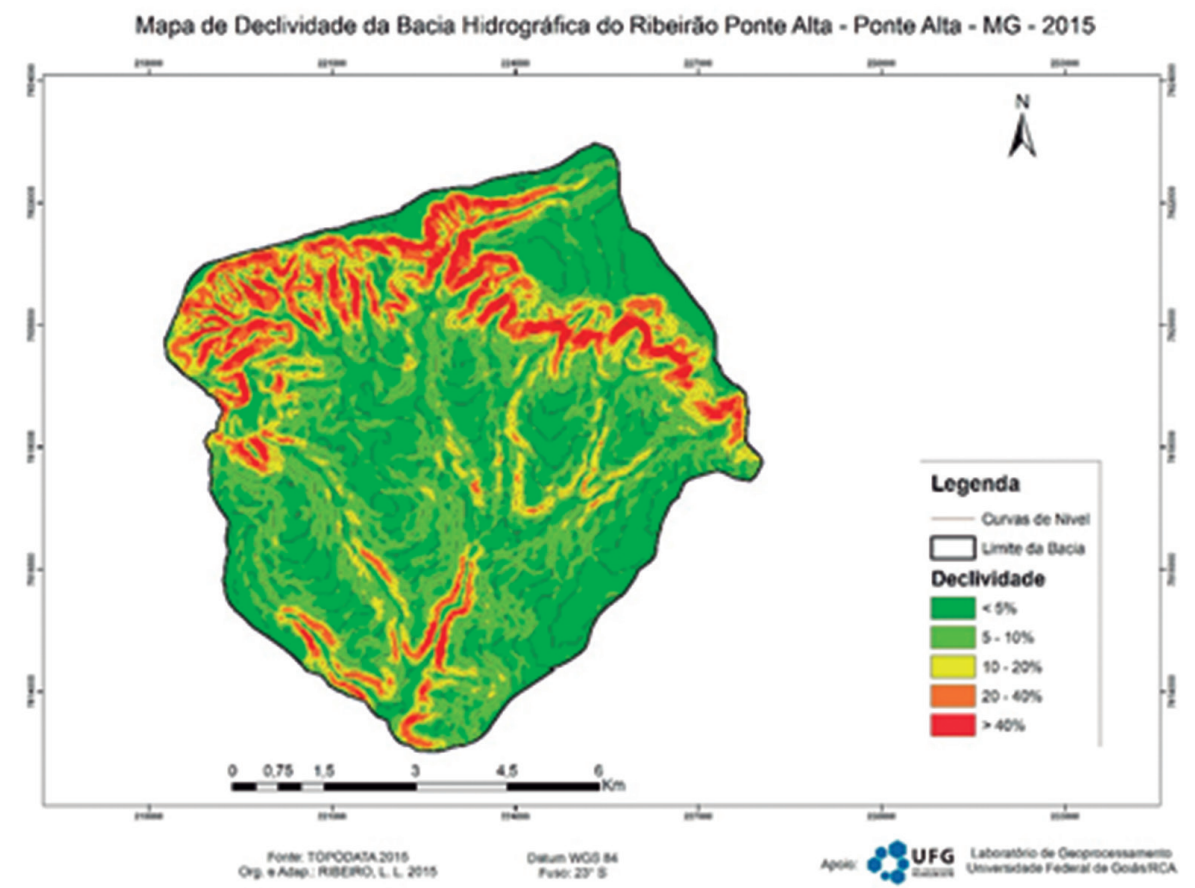

Figura 2. Mapa de declividade da bacia hidrográfica do Ribeirão Ponte Alta-MG, 2015. Fonte: Ribeiro (2015).

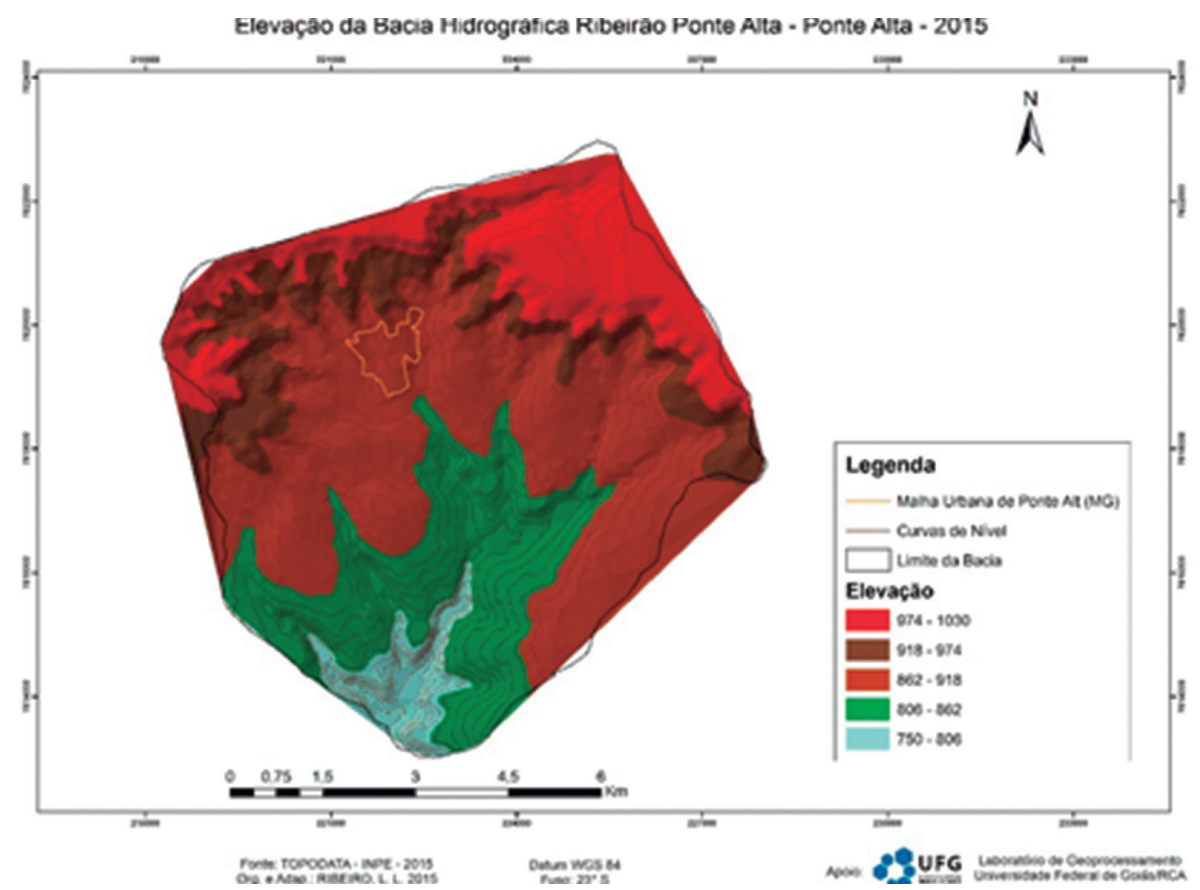

Figura 3. Mapa Hipsométrico da bacia hidrográfica do Ribeirão Ponte Alta-MG, 2015. Fonte: Ribeiro (2015). 
Ao interpretar os mapas temáticos de uso e de ocupação da terra da Figura 4 e da Figura 5, nota-se que, em 1985, nas áreas caracterizadas como mais planas, as terras serviram para a agropecuária e para a agricultura, porém, essas atividades foram intensificadas e isso pode ser observado na imagem de 2015. Pode-se perceber que essas atividades estão dentro de áreas propriedades de fazendeiros. As atividades agropecuárias predominam mais no médio e baixo curso da bacia, que é dividida entre culturas permanentes e temporárias.

USO E OCUPAÇÃO DA TERRA DA BACLA HIDROGRÁFICA DO RIBEIRÃO PONTE ALTA - UBERABA (MG) - 2015
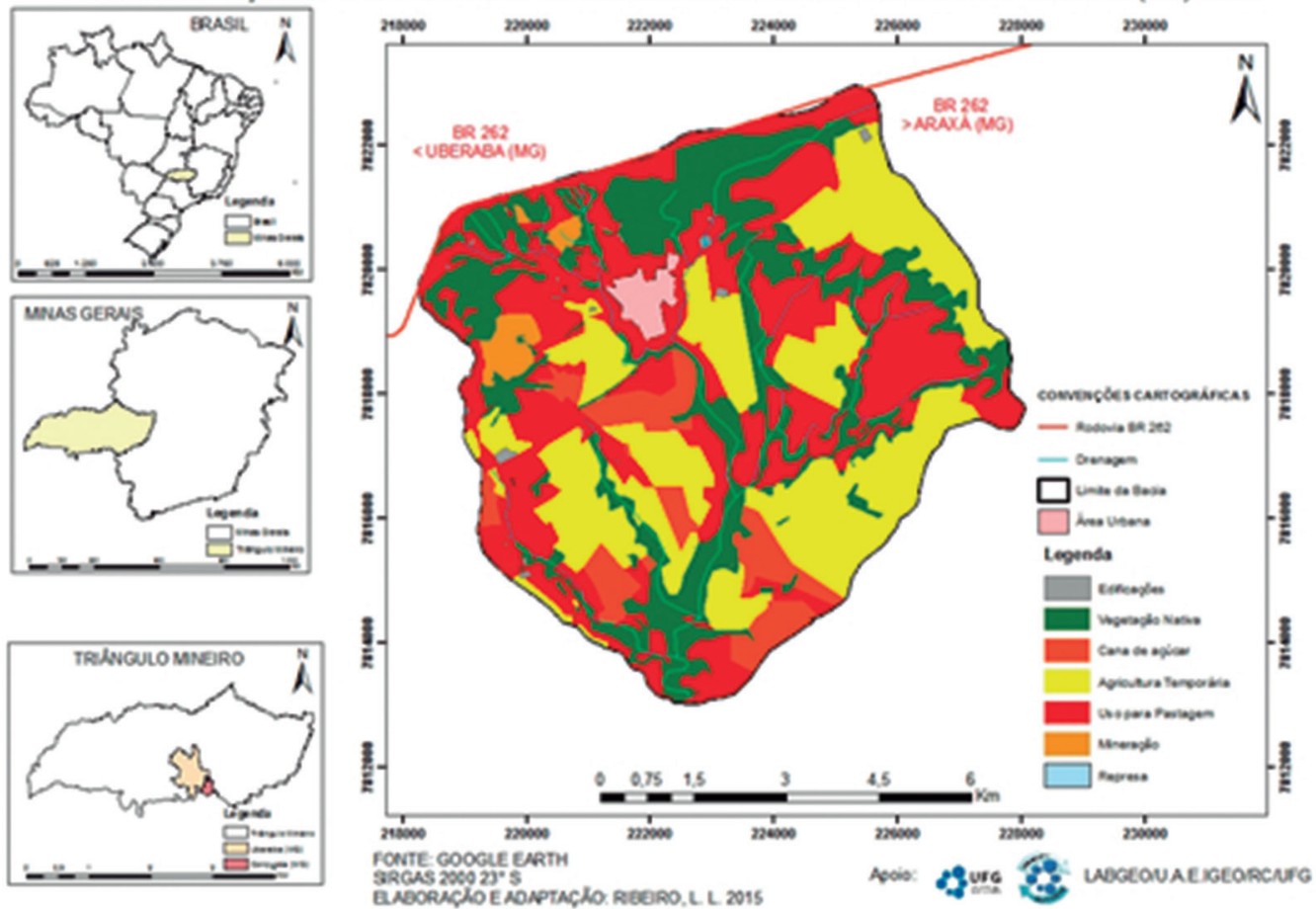

Figura 4. Mapa de uso e ocupação da terra da bacia hidrográfica do Ribeirão Ponte Alta-MG, 2015. Fonte: Ribeiro (2015).

Observa-se que houve maior concentração e crescimento urbano no que diz respeito à área de nascentes, o que pode ocasionar uma mudança de vazão para os recursos hídricos da região.

O uso e a ocupação das áreas de dissecação, como é o caso da bacia em estudo, amplamente prevalecem na distribuição da área da bacia e interferem fortemente na dinâmica dos recursos hídricos e no equilíbrio natural da paisagem. 


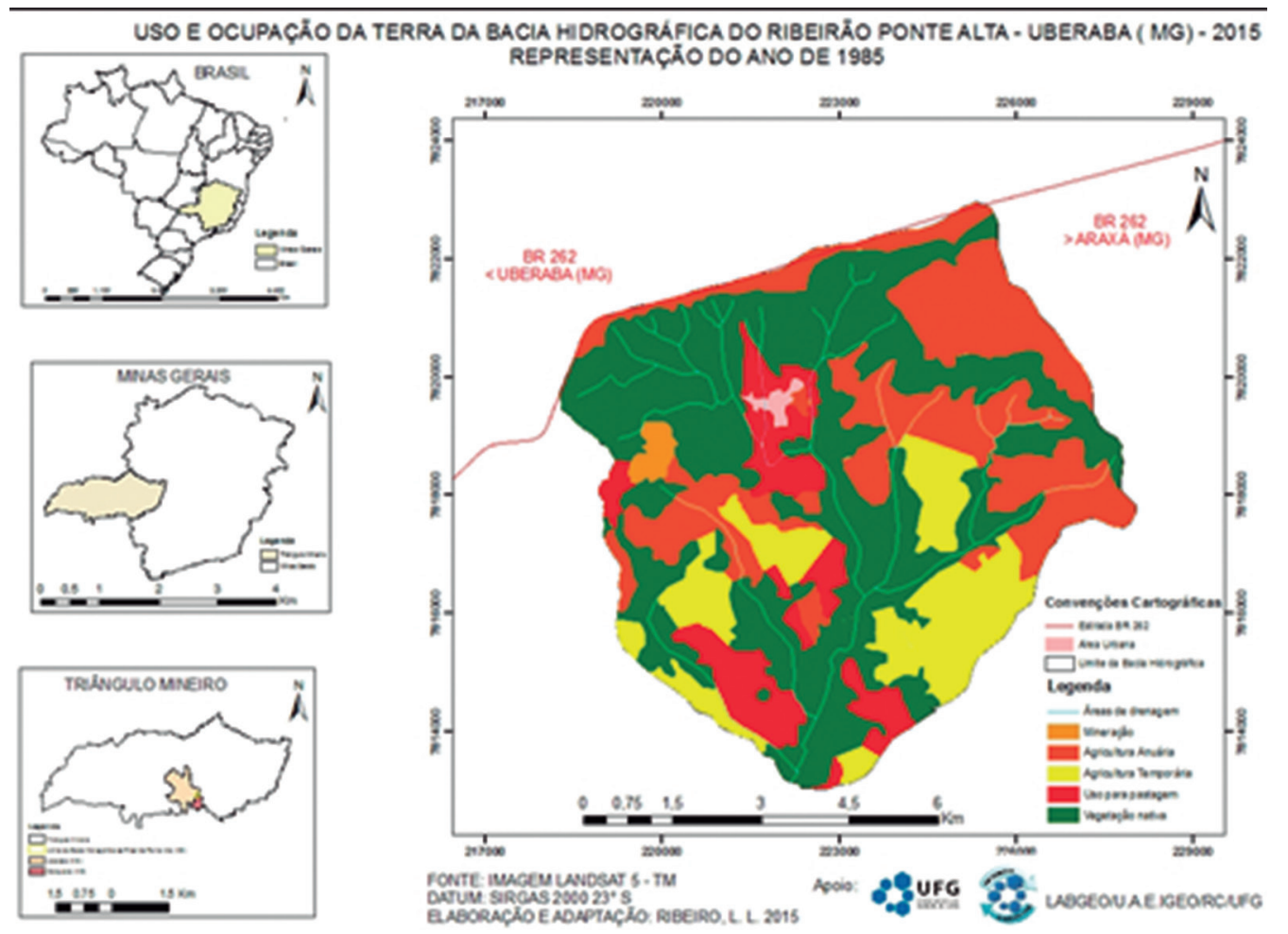

Figura 5. Mapa de uso e ocupação da terra da bacia hidrográfica do Ribeirão Ponte Alta-MG, representando o ano de 1985. Fonte: Ribeiro (2015).

Ao analisar o mapeamento temático de uso e de ocupação da terra, representado na Figura 5, observamos que a vegetação nativa da região está bastante notória e pouco devastada. Isso se explica pelo fato de a urbanização da área estar apenas no início assim como está no início a exploração da área, relacionada à extração de calcário.

Percebe-se que houve um aumento da área degradada quando se compara o ano de 2015 ao ano de 1985. Observou-se que no ano de 1985, havia uma maior cobertura vegetal.

A área da bacia hidrográfica do Ribeirão Ponte Alta-MG é uma área frágil que, mesmo em locais onde a declividade é alta -como em suas nascentes -, encontram-se testemunhos de uso inadequado no ambiente. Percebe-se, ainda, o acesso do gado em determinados locais e a fraca presença de vegetação protegendo o solo, principalmente onde ocorrem as atividades de agricultura e de pastagem. Pode-se também afirmar que as áreas de exploração e desmatamento foram mais acentuadas nos últimos anos. 
Nas nascentes próximas de onde ocorreram as explorações, foi possível notar que o acesso está dificultado. A vegetação nativa encontrada pode ser caracterizada como mata ciliar. Onde ocorriam os eventos de exploração de minérios, a área está se recuperando; além disso, há um cercamento para o gado, fator positivo para a preservação da área, desde a época da exploração. Foi tomada esta cautela para impedir a entrada de animais, devido à alta periculosidade das atividades que ocorriam lá.

Este artigo apresentou uma visão geral das aplicações de técnicas simples de Sensoriamento Remoto aplicadas ao problema de mapear as categorias de capacidade de uso da terra. Pode-se analisar que o meio físico da área estudada tem o uso e a ocupação mais dedicados às agriculturas temporárias, cana-de-açúcar e pastagem. Isso ocorre porque essa parte da área tem um relevo mais aplainado, que facilita esse tipo de atividade.

\section{CONCLUSÃO}

O artigo demonstrou de forma clara como se encontra a área estudada. Por meio das categorias relacionadas no mapeamento temático de uso e de ocupação da terra, pode auxiliar em ações gerais para uma gestão ambiental adequada do meio ambiente. Adicionalmente, os resultados podem servir de instrumento valioso contra as ações de antropização.

A análise da imagem satélite Landsat-TM 8 e 5 a partir da ferramenta do SIG Arcgis atendeu às proposições feitas neste artigo, permitindo, além de caracterizar o uso e cobertura da terra da área de estudo, delimitar e avaliar espacialmente a situação das áreas de nascentes. O trabalho confirmou a complexidade de usos e de situações espaciais de ocupação encontradas e a importância de manter preservadas as áreas de nascentes.

É relevante que os órgãos competentes tomem ciência do potencial de uso das ferramentas de geotecnologias livres e gratuitas como estas para apoio à gestão. A utilização das ferramentas de uso livre contribui com a fiscalização por parte dos órgãos responsáveis ao reduzir custos e tempo, porém há necessidade de idas a campo para determinar as características reais, pois estas podem sofrer alterações com os plantios. Assim, a importância da fiscalização para conservação e recuperação ambiental está ligada à conservação dos recursos hídricos.

\section{AGRADECIMENTOS}

Nossos agradecimentos à CAPES (Coordenação de Aperfeiçoamento de Pessoal de Nível Superior) e, também, à Universidade Federal de Goiás - Regional de 
Catalão, pela oportunidade de realizarmos essa pesquisa e por nos fornecerem os meios necessários para o seu desenvolvimento e a sua condução.

\section{REFERÊNCIAS}

BRASIL. Lei Complementar $n^{\circ}$ 413/2009. Altera dispositivo da Lei Complementar $n^{\circ}$. 359, de 05 de dezembro de 2006, alterada pela Lei Complementar nº. 385, de 19 de julho de 2007. Uberaba, MG. Disponível em: <http://www.uberaba.mg.gov.br/portal/ acervo/plano_diretor/arquivos/plano_diretor_e_legislacao_urbanistica/lei_plano_diretor/ lc_413/lc_413.pdf >. Acesso em: 28 abr. 2015.

CARDOSO. A. R. et al. Geotecnologias aplicadas em estudos ambientais. In: POLETO. C. (Org.). Introdução ao gerenciamento ambiental. Rio de Janeiro: Editora Interciência, 2010. 354 p.

DE BIASI, M. A carta clinográfica: os métodos de representação e sua confecção. Disponível em: <http://www.geografia.fflch.usp.br/inferior/laboratorios/lcarto_ori/ PAGINA\%20DO\%20LABCART/artigos/artigo02.html>. Acesso em: 07 mai. 2015. EMBRAPA MONITORAMENTO POR SATÉLITE. O Brasil visto do espaço. Brasil: Ministério da Agricultura, Pecuária e Abastecimento, 2004. Disponível em: <http:// www.cdbrasil.cnpm.embrapa.br/projeto.htm>. Acesso em: 25 fev. 2015.

FITZ, P. R. Geoprocessamento sem compilação. São Paulo: Oficina de Textos, 2008. 160 p. FLORENZANO, T. G. Iniciação em sensoriamento remoto. 3. ed. São Paulo: Oficina de Textos, 2011. 128 p.

GIANEZINI, M. et al. Geotecnologia aplicada ao agronegócio: conceitos, pesquisa e oferta. Economia \& Tecnologia, v. 8, p. 168-174, 2012.

INCRA - Instituto Nacional de Reforma Agrária. 2006. Manual de obtenção de terras e perícia judicial. $140 \mathrm{p}$.

PREFEITURA MUNICIPAL DE UBERABA. Secretaria de Infraestrutura. 2008. Disponível em: <http://www.uberaba.mg.gov.br>. Acesso em: 20 dez. 2014.

RIBEIRO, L. C. B. et al. Geoparque Uberaba - terra dos dinossauros do Brasil (MG): proposta. 2010. v. 1. Disponível em: <http://www.cprm.gov.br/publique/media/ dinossauros.pdf $>$. Acesso em: 24 maio 2016.

ROSA. R. BRITO. J. L. S. Introdução ao geoprocessamento: sistema de informação geográfica. Uberlândia: EDUFU, 1996. 104 p.

SANTOS, C. Z. Alterações socioambientais na bacia hidrográfica do ribeirão do Lajeado no município de Paraibuna - SP. 2007. 1 CDROM. Dissertação (Mestrado em Planejamento Urbano e Regional) - Instituto de Pesquisa e Desenvolvimento, Universidade do Vale do Paraíba, São José dos Campos. 2007.

SANTOS. R. F. Planejamento ambiental: teoria e prática. São Paulo: Oficina de Textos, 2004. 
SILVA. J. X.; ZAIDAN. R. T. Geoprocessamento e análise ambiental: aplicações. Rio de Janeiro: Bertrand Brasil, 2012. 366 p.

TRICART. J. Ecodinâmica. Rio de Janeiro: IBGE, 1977. 35 p. 